\title{
Communication Between Organ Donor Families and their Recipients is Therapeutic in the Great Majority of Cases
}

\section{Reg Green*}

Nicholas Green Foundation, USA

*Corresponding Author: Reg Green, Nicholas Green Foundation, USA.
Received: September 20, 2021

Published: October 25, 2021

(C) All rights are reserved by Reg Green.

\begin{abstract}
The health and happiness of the families of organ donors and their recipients are improved in the great majority of cases when the two sides are allowed to communicate with each other, if both sides have expressed such a desire. Communication may be either by letter or in person, depending on the wishes of the two families. Yet both are made difficult or impossible in most countries because of fears that one side or the other might suffer psychological damage. The evidence presented in this paper shows those fears are usually unfounded. In fact, the health of both sets of families is more likely to be harmed when they are kept apart.
\end{abstract}

Keywords: Maggie; Organs; Donor

Donating the organs of a loved one who has just been declared brain dead is one of the most selfless acts in medicine: for many families the temptation to turn inward in grief or bitterness is irresistible. Others are too numb to make major decisions about something so momentous. Still others are horrified at the idea of tampering with the body.

Brain death is usually sudden death: such as a road accident, a stroke or violence. The family has had no preparation for it -- unlike most deaths -- and it often happens to people who are painfully young or in perfect health.

For a family to be asked there and then to make a decision that will benefit people they have never met and cannot even visualise is too much for many and they say no, only realizing later that they have probably given up the best chance they will ever have to make the world a better place. A noble percentage of others, however, go through with it.
My wife, Maggie, and I, who live in California, became involved when our seven-year old son, Nicholas, was shot during a botched robbery while we were on a family holiday in Italy. He was an enchanting little creature. His teacher said he was the most giving child she had ever met and she always knew he was her teacher.

When the doctors told us he was brain dead it seemed to empty all meaning out of life. I grappled, as if in a fog, with the realization that we'd had the last of our hikes, full of adventure and fun, and that I would never again hear him say "Goodnight, Daddy".

But, although Maggie was equally heartsick, she had the presence of mind to see that some good could come out of it. "Now that he's gone, shouldn't we donate his organs?" she said quietly. Until that moment everything had been totally bleak. But now I too realized his death could be more than a complete waste.

We told the doctors we wanted to donate: they seemed surprised but pleased. Later we found that Italy had almost the lowest 
rate of donations among similar countries so every donation was especially precious there.

The good that came out of it was, in fact, far greater than anything we could have imagined: organ donations in Italy soared in the next few weeks -- not just registrations to become donors, but actual donations -- and they kept on growing. In the following ten years donation rates tripled -- a rate of increase no other country has come anywhere near -- and thousands of desperately sick people were returned to good health [1].

Nicholas' organs saved the lives of five people and his corneas prevented two others from going blind. The story, making headlines and leading news programs everywhere, captured the world's imagination as tens of millions of people realized for the first time that if one of their family became brain dead they too could do that much good by a simple 'yes'.

The medical establishment was equally impressed. Maggie and I were invited to tell our story at conferences around the world. Some of the world's leading medical journals, including the Journal of the American Medical Association, asked me to write articles for them [2].

\section{The recipients}

The recipients had all been severely ill. Four of them were teenagers. Maria Pia Pedala, a 19-year old from Sicily, for example, was in her final coma from liver failure on the day that Nicholas died. The doctors had given up on her. Her family, which had already suffered more than its fsair share of losses, prepared itself for another.

But, instead, she woke with a new liver, bounced quickly back to good health and two years later married her faithful sweetheart, Salvatore. Two years after that she had a baby boy -- something that would have been unthinkable before the transplant -- and, yes, she called him Nicholas.

Andrea Mongiardo, the 15-year old boy who got Nicholas' heart, was being given transfusions of blood products twice a week, he was grossly under-nourished and shuffled around like an old man. When he went to bed he never knew if he would wake up in the morning. For all practical purposes his life was over. The transplant immediately put him out of danger and in time he recovered so well that he got a job and could even play soccer. His cousin, Valentina
Lijoi, once told me that Andrea used to tell people that instead of having a broken-down old jalopy inside of him he now had a Ferrari [3].

Anna Maria Di Ceglie, aged 14, and Tino Motta, 10, kidney patients whose childhoods had been ruined by being on dialysis and having to spend four hours a day, three days a week hooked up to machines that cleansed their blood, were freed from that imprisoning regimen; Silvia Ciampi, a diabetic who was going blind and was so frail that she depended on others for the simplest tasks, was able to move into an apartment of her own for the first time in her life; two adults, Domenica Galletta and Francesco Mondello, who each received a cornea, could play with their young children again.

\section{We met all the recipients}

We know all this because in those days donor families in Italy, unlike those in most other countries, were allowed to meet their recipients, which we did four months after the transplants. I had expected mixed feelings but the sight of those young people so full of life overcame the dejection. To realize that our little boy had made all this possible added a touch of magic to their laughter. I wrote a book about it called "The Nicholas Effect" [4].

Our own family saw a major change too: reluctant to let Nicholas' four-year old sister, Eleanor, grow up an only child, after having had such a loving brother, we made a major decision and a little over two years after we lost Nicholas, Maggie gave birth to twins, Laura and Martin, who filled up the house as nothing else could have done.

All seven of the recipients told the world on television and in print how their lives had been transformed and what they could do now that had been impossible before. We have met them all again since then, some of them several times. All of them have said they have been glad to know us: they could see for themselves that we don't hold it against them that they are alive only because Nicholas died. They have the proof of their own eyes that if they are happy it reinforces our feeling that the donation was worthwhile. Nicholas had brought with him on vacation his favorite toy: a set of US cavalrymen, in whom he saw the honorable behavior, courage and decency that idealistic boys respect so much. When Maggie gave one to each of the recipients they looked as though they had been handed a present from heaven [5]. 
Similar meetings are now prevented

Unfortunately such meetings are now virtually impossible in many countries, including Italy, because of laws brought in largely due to mistaken fears that any contact between the two sides might be upsetting to one or other side.

Suppose the donor family doesn't like the recipients, opponents of contacts ask, will they wish they hadn't agreed to donate? What if a strongly religious family of donors finds out the recipients are of a different faith? What if the donor family had lost a child and had set its heart on saving other children but instead finds all the organs went to grown ups? Suppose the transplant fails: will the donor family regret their decision?

The fears, though they are still cited, are hugely overblown. Families who are willing to donate have already survived a crushing experience. Few of them doubt that saving the lives of several other people is far more important than whether those people have a lifestyle similar to their own. By signing the consent form they have agreed the organs will go to those who are most in need and that is what they want.

Many transplant families suffer when contact is denied.

Those who oppose change often forget that there is a price to be paid for privacy. Donor families who know almost nothing about their recipients often feel something is missing in their lives: they don't even know if the people they saved are still living. Most don't let it worry them unduly -- they know they made the right decision and don't need to know more -- but substantial numbers of others never get used to the uncertainty. Did we do any good? they fret. Did we simply prolong sickly lives? Like most of us they prefer bad news to no news at all. It's shabby treatment, I hope you will agree, for people who gave so much to others.

Many recipients yearn for contact too. They feel guilty because they are alive only because someone else died: they want nothing more than to say thank you to the people who saved their lives.

\section{Contact is therapeutic}

Luckily, we don't have to depend on anecdotes to work out what the most beneficial policy is. For the last thirty years contact, both by letter and face-to-face, has been encouraged in the United States under conditions set by the health service and overseen by the families' medical advisers. Tens of thousands of these contacts have been made and in the great majority of cases the results have been positive. These contacts are handled by 57 organ procurement organizations, staffed by specially-trained doctors, nurses and other health professionals that work hand in glove with hospitals in their area and are responsible to the US Department of Health for the welfare of both transplant recipients and donor families. All 57, without exception, speak of the healing power these communications produce. This is what the chief executive officers of some of them say: Kathleen Lilly, Executive Vice President of LifeLink Foundation, which covers areas as diverse as the modern cities of central Florida, rural portions of Georgia, the high-class tourism of the U.S. Virgin Islands and Spanish-speaking Puerto Rico, says “Our foundation's experience with donor family and recipient communication has been overwhelmingly positive for all involved".

At the opposite corner of the country is LifeCenter Northwest, whose territory includes states in the northwest of the United States and Alaska. Its CEO, Kevin O'Connor, says the same thing : "The ability to exchange letters between donor families and recipients is profoundly healing and therapeutic for both parties".

And in the middle of the country, Jennifer Prinz, CEO of Donor Alliance, the organ procurement organization covering Colorado and most of Wyoming, agrees. "Correspondence between donor families and recipients is a tremendously powerful and positive practice in the donation. We see many donor families and recipients go on to have incredibly close, family-like relationships, across many years and great distances", she says.

"For the overwhelming majority, contacts between recipients and donor family members provide comfort to both sides", says Howard Nathan, Gift of Life Donor Program, the organ procurement organization that covers a part of Pennsylvania and Maryland, an area with a population of 11 million.

"The majority of our donor families and recipients that meet go on to create life-long friendships", Suzanne Conrad, Iowa Donor Network, reports.

"These contacts provide healing to both sides, many have created life-long friendships, and all enable those touched by donation to share their experience, if they wish, with anyone from their closest friends to the world at large -- giving anyone who hears them an incentive to become a donor too, "says Tom Mone of OneLegacy, 
whose area in California covers twenty million people and two hundred hospitals.

The unanimity is impressive, isn't it? Doubly so, because these are the organizations that stay closest to the transplant families: they know them personally, care about them as individuals and would vigorously oppose policies that they thought might harm them.

\section{'The Italian Campaign' to free contacts}

All this evidence, statistical and personal, is at last making headway in countries that traditionally discourage contacts. The most dramatic example is Italy where five years ago the whole subject was taboo.

I often raised the question in private conversations there with doctors and health care administrators but no one thought repeal of the law was feasible, most thought it was also undesirable and those who agreed preferred not to get involved in such a controversial issue.

In 2016, however, I realized that at 87 years of age I might not have many more opportunities to bring the topic into the open and so, after more than twenty years of maintaining silence on this issue, I took a deep breath and began systematically contacting the media to start a national discussion. I was surprised and gratified by the response.

The editors I talked and wrote to understood instinctively the yearnings of people involved in these transplant situations. However, I made sure to let them know the concerns of both the main medical institutions and individual physicians, gave them contact information in both Italy and the US so they could do the research themselves and answered a barrage of questions.

\section{Don quixote and sancho panza}

I had just one partner, Andrea Scarabelli, from Rome who when a university student of 21 was one of many hundreds of Italians who wrote to Maggie and me when Nicholas died. Andrea became a friend and, now in his forties, has been an invaluable guide in steering me through the complexities of a country I love but am still a foreigner in. Without him, I feel sure, the campaign would have fizzled out. Not a single doctor or health official would join us, however, and we became known as Don Quixote and Sancho Panza.
But momentum was building and some of the largest newspapers, magazines and television programs began featuring stories asking whether, after all, there was any real justification for preventing the two sides from even writing to each other anonymously.

I wrote articles for medical journals, gave interviews to anyone who would listen, gave speeches to audiences ranging from college students to the national association of transplant surgeons, talked at hospitals to both the medical staff and patients. Interest snowballed, reaching tens of millions of viewers and readers and all over Italy people began to ask, "If two families with such a bond want to contact each other, why should some bureaucrat who knows nothing about them tell them it is not allowed?"

We began to get help from people who had given organ donation little or no thought before tragedy had struck them (just like us!) One stood out: Marco Galbiati, whose teenage son, Riccardo died on a ski slope in 2017. Anxious to know who Riccardo had helped, he recognized the change in public opinion and sent out a petition online calling for a change in the law that was signed by fifty thousand people. Using that demonstration of public support, he threw his influence into the politics of reform.

The skeptics remained unconvinced. Again and again we were asked, wouldn't the health of the two sides suffer if they didn't like each other? What if one party wanted a much more intense relationship than the other? What if members of the donor family told the recipients they needed money and expected someone whose life they had saved to help them out?

\section{How it works in real life}

All those nightmare scenarios are possible, of course. But the actuality is in the statistics: in the tens of thousands of cases where the two sides have communicated in the United States only a small minority have gone wrong. And even then the problem has normally been dealt with easily and quickly.

Partly that is because transplant families have had to deal with far more difficult problems. Almost by definition they are not weak people. The thought that they are helpless to deal tactfully with potentially embarrassing situations is to seriously under-estimate them. But in addition formidable rules have been worked out based on decades of experience. 
First, no communication is allowed at all unless both parties express a desire for it. If they do, the normal procedure is for one of the families to write an anonymous letter to the other with information about itself. That letter is examined by their hospital to make sure nothing abnormal is in it, nothing that suggests the writer is uncomfortably possessive, for example. It is then passed to the other family. If they do not want to start a relationship, the process ends there, however insistent the first family is.

If that second family does want to reply, however, it does so, also anonymously and also through the hospital. The two sides can continue anonymous correspondence for as long as they wish or they can reveal their identity. Sometimes there is frequent exchange of letters, sometimes just on rare occasions - on the anniversary of the transplant, for example, or a birthday.

Anonymous letters may sound a little dry but imagine the thrill of receiving one from the teenager who tells you that at one time he could not walk to the door of his apartment without stopping to recover his breath but can now play soccer. Or an elderly lady who. against all expectations, has just seen her grand-daughter graduate from college. Or a man who had been in a wheelchair but has just run a marathon.

The excitement of living a normal life radiates from those unsigned pages tinged with profound gratitude.

In time the parties may decide they want to meet, their hearts beating wildly as the day approaches. Sometimes, as the critics say, the differences between the two sides are too great for them to want to meet again but more often, much more often, the two sides seem to melt into each other's arms.

The story of Inger Jessen typifies the kind of emotions that faceto-face meetings produce. She has not had an easy life, having lost both a husband and a son and a leg amputated because of diabetes. When she received the heart that saved her life, she wrote an unsigned letter through OneLegacy, the organ procurement organization in Southern California, hoping it would bring some consolation to the donor family [6].

They were glad to receive it but too devastated by the loss of their 18-year old daughter, Nicole, to want to carry the relationship further. Nicole's father, Dan Mason, remembers how he had no feeling for anything. "Sometimes when I was driving I had to pull over to the side of the road to sob", he says. "I had a four-yearold grand-daughter and I couldn't even play with her". The Masons didn't reply to Inger and she resigned herself, sadly, to never knowing who to thank.

Twenty years passed under the weight of this sorrow but for the Masons too it began to seem right to know more about this kindly lady with whom they had such an unusual bond. They contacted OneLegacy, saying they would like to meet. Inger says that for days after she received the call, she went around in a dream.

On the $20^{\text {th }}$ anniversary of Nicole's death they met and were instantly enveloped in an atmosphere of mutual love, the climax coming when the Masons listened by stethoscope to the strong, regular beat of their daughter's heart, which has worked perfectly from the start. "I couldn't believe I was listening to Nikki's heart", Dan recalls. "I think of her every day. She seems so far away. But here she was again".

For Inger too the meeting was all she had hoped for. "Since then", she says, "I have felt a peace I haven't known in years".

Readers who want to see a fictionalized but true-to-life version of such a meeting might want to view the made-for-television movie, "Nicholas' Gift", starring Jamie Lee Curtis that was based on my "Nicholas Effect" book [7].

Why wouldn't it be that way? One side is meeting someone to whom they made a great gift and who is eternally grateful for it, the other is meeting someone who had the warmth of human understanding to help them, a perfect stranger, when no one else could. In most cases it is a natural fit.

The people who choose to meet face to face are only a small proportion of those who write to each other - it is after all a step into the dark - but the volume of communications should put to rest any idea that families are not interested in contacting each other: in the United States in 2019, a survey of a total of 24,000 letters were forwarded through OPOs from one side to the other. And that excludes any communications -- letters, email, phone calls, faceto-face meetings -- that the two sides made between themselves, and not through the OPOs, which they can do once their medical advisers no longer think their oversight is necessary [8]. 
Admittedly conditions are different in every country and many practices would have to be modified, but I refuse to believe American grief is so much different from grief in the rest of the world that principles that work so well here would be ineffective in other countries.

The campaign becomes a tidal wave

Andrea and I bombarded the Italian National Bioethics Committee -- the highest body in the land in matters like these -- with all this evidence, much of which was entirely new to them and when their report came out, it recommended a change in the law allowing contacts to take place under just the kind of controlled conditions we had been calling for.

The Italian National Health Institute studied this evidence and endorsed the recommendation in its official journal under the title, "Organ donor families should be free to meet their recipients under controlled conditions if both sides wish, Italian National Bioethics Committee says" [9].

The other healthcare institutions with a responsibility for the subject -- including the National Transplantation Center -- added their agreement.

By now, our lonely campaign had become a tidal wave. The national government studied it too and a statement by the Deputy Minister of Health, Dr. Pierpaolo Sileri added his glowing approval.

"The liberalization of contacts between recipients and donor families is a deed of humanity and civilization, a right and proper act that must find its rightful position in a modification of the current legislation,... I want to thank once again Nicholas' family who, without their faith in humanity and will to contribute to our emancipation as persons, wouldn't have ever pursued the path of the gift and the campaign for a liberalization. It means having your neighbor at heart and waging a battle like Don Quixote, as Reg Green, Nicholas' father, says in his own words".

\section{Postscript}

By pure coincidence I am writing this paper on what would have been Nicholas' 34th birthday and that, of course, has flooded my mind with memories. One is something Maggie wrote about him a year or two after he was killed. I hope you can feel in it that a decision to let a loved one be an organ donor takes nothing away from that love. "His hair looked so beautiful, growing in careless curls around his head", she said. "I only cut it so people would know I cared".

\section{Conclusion}

The evidence presented in this paper shows those fears are usually unfounded. In fact, the health of both sets of families is more likely to be harmed when they are kept apart.

\section{Bibliography}

1. Annual Report on Italian Organ Donation. (Living donation are shown in light green for kidneys, orange for liver) (2020).

2. A Piece of My Mind Journal of the American Medical Association Ed. Roxanne K. Young P. 140 AMA Press (2000).

3. Visto magazine December (2020).

4. The Nicholas Effect by Reg Green (publisher www.authorhouse.com 2009).

5. Nicholas Effect Chapter 8.

6. OneLegacy Foundation 221 South Figueroa St. Suite 500 Los Angeles CA 90012.

7. https://www.imdb.com/title/tt0143767/

8. OPO Aftercare Survey, Association of Organ Procurement Organizations, 8300 Greensboro Drive, \#L1-620 | McLean, VA 22102 USA.

9. Carlo Petrini and Reg Green. "Organ donor families should be free to meet their recipients under controlled conditions if both sides wish, Italian National Committee for Bioethics says". Annali Istituto Superiore di Sanità (ISS) 55.1 (2019).

\section{Volume 3 Issue 11 November 2021 CAll rights are reserved by Reg Green.}

